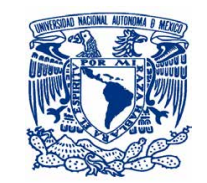

\title{
LOS MAMÍFEROS DE LA ISLA DE OMETEPE EN EL LAGO COCIBOLCA, PACÍFICO
}

\section{SUR DE NICARAGUA}

\author{
Arnulfo Medina-Fitoria
}

Asociación Mastozoológica Nicaragüense - AMAN; Managua, Nicaragua.

\section{Resumen}

En este estudio se describe la riqueza mastozoológica de la isla de Ometepe, una isla volcánica que se encuentra en un lago de agua dulce. Tanto el carácter insular como su posición geográfica derivan en una singular variedad de ecosistemas naturales como son bosque nuboso, bosque húmedo de influencia Caribeña, el típico bosque seco del Pacífico, coladas de lava y humedales, que en su conjunto albergan poblaciones faunísticas de gran importancia ecológica y social. Una interesante historia evolutiva y de colonización ha dado cabida a una diversidad actual de 51 especies de mamíferos silvestres en la isla, que representa el $26 \%$ de los mamíferos continentales del país, incluidas dos especies introducidas con poblaciones silvestres. El $78.4 \%$ del total de especies son micromamíferos (murciélagos y roedores),así como no hay evidencia de grandes depredadores o especies con importantes requerimientos de hábitat. Asímismo se formalizó la presencia de seis especies en la isla. Estas son: Lampronycteris brachyotis, Lonchorhina aurita, Micronycteris microtis, Trinycteris nicefori, Chrotopterus auritus y Natalus mexicanus, que, aunque fueron incluidas en informes técnicos, no estaban apoyadas por ninguna publicación científica. Finalmente en esta investigación se evidenció la extinción de una especie de la isla: el mono araña Ateles geoffroyi.

Palabras clave: distribución, diversidad, extinción, hábitat.

Revisado: 09 de abril de 2019; aceptado: 04 de junio de 2019; publicado: 15 de julio de 2019. Autor de correspondencia: Arnulfo Medina-Fitoria, amedinafitoria@gmail.com.

Cita: Medina-Fitoria, A. 2019. Los mamíferos de la isla de Ometepe en el lago Cocibolca, Pacífico Sur de Nicaragua. Revista Mexicana de Mastozoología, nueva época, 9(1):01-19. ISSN:20074484. www.revmexmastozoologia.unam.mx

\section{ReleVANCIA}

Se presenta una lista actualizada de los mamíferos de la isla volcánica de Ometepe, en el Pacífico sur de Nicaragua. Se reportan 51 especies, su distribución, amenazas y estado de conservación. Y se indician prioridades para su conservación.

\section{Abstract}

The mastozoological richness of Ometepe Island is described, a volcanic island in a freshwater lake. The insular character and its geographic position derive in a singular variety of ecosystem: cloud forest, humid forest of Caribbean influence, the typical dry forest of the pacific, lava flows and wetlands, which as a whole host faunal populations of great ecological importance and Social. An interesting evolutionary and colonization history has accommodated a current diversity of 51 species of wild mammals on the island representing $26 \%$ of the country's continental mammals, including two introduced species with wild populations. The $78.4 \%$ are micromammals (bats and rodents) just as there is no evidence of large predators or species with large habitat requirements. It was also formalized the presence of six species on the island. These are: Lampronycteris brachyotis, Lonchorhina aurita, Micronycteris microtis, Trinycteris nicefori, Chrotopterus auritus and Natalus mexicanus, which, although included in technical reports, were not supported by any scientific publication. Finally in this investigation the extinction of a species on the island: the spider monkey Ateles geoffroyi.

Key words: distribution, diversity, extinction, habitat. 


\section{INTRODUCCIÓN}

La isla de Ometepe se ubica en el lago Cocibolca y tiene dos volcanes: Concepción y Maderas (Figura 1). Debido a su condición insular y posición geográfica, es un área de transición entre la región seca del Pacífico y la región húmeda del Caribe, lo que da origen a una biodiversidad singular (Gillespie, 1994). En total, 239 especies de vertebrados terrestres han sido identificados en la isla, de los cuales, 148 son aves, 51 mamiferos, 31 y nueve anfibios. De estos últimos uno es endémico: la salamandra de volcán Maderas Bolitoglossa insularis (Morales et al., 2007; Sunyer et al., 2008).

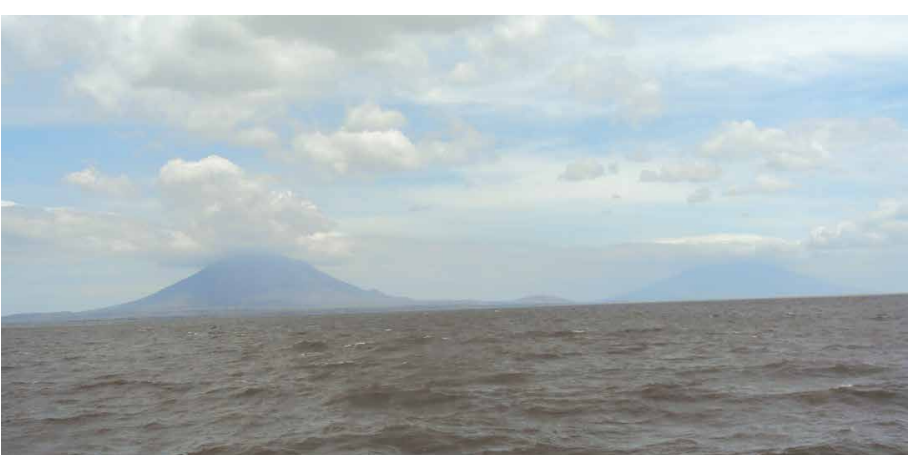

Figura 1. Vista de la Isla de Ometepe, Nicaragua. Foto: Arnulfo Medina.

\section{Análisis evolutivo y reseña histórica}

La paleontología de vertebrados indica que el arco volcánico centroamericano fue una península norteamericana que se extendía posiblemente hasta Panamá (Kirby y MacFadden, 2005; Lucas, 2014). Esto sugiere que las primeras especies de fauna en Centroamérica llegaron del norte, lo cual es respaldado por el único fósil de dinosaurio centroamericano de $95 \mathrm{Ma}$ (millones de años), encontrado en Honduras y de origen norteamericano (Horne, 1994). La variación de los niveles del mar por cambios climáticos globales, permitieron la llegada de aves del sur en el Oligoceno (25 Ma), seguido de mamíferos en el Mioceno, $23 \mathrm{Ma}$, (Pelegrin et al., 2018). Asimismo, fósiles de Panamá del primate Panamacebus (21 Ma) evidencian la llegada temprana de mamíferos neotropicales (Bloch et al., 2016). Sin embargo, fue la formación del istmo de Panamá lo que facilitó un mayor intercambio de fauna, que alcanzó mayor magnitud hace $2.5 \mathrm{Ma}$ en los periodos interglaciales del Pleistoceno (McPherson, 1985). De esta manera es posible encontrar en
Ometepe especies de ambas latitudes como venados cola blanca y conejos provenientes del norte, con primates, tamandúas, armadillos y zarigüeyas del sur (Pelegrin et al., 2018).

La existencia de dos especies de didélfidos en los volcanes de Ometepe sugiere una antigua conexión terrestre con el continente de hace 0.8-0.7 Ma, tiempo estimado en que este linaje salió de Sudamérica (Cione et al., 2015; Woodburne, 2010). Esta conexión comenzó a perderse posiblemente con el surgimiento del Caribe Centroamericano, uno de los últimos movimientos de masas que unieron al continente en el pleistoceno hace $2.5 \mathrm{Ma}$ (Weyl, 1980) y que continuó con la formación del graben nicaragüense originado por un hundimiento tectónico hace $2 \mathrm{Ma}, \mathrm{y}$ que creó los lagos Xolotlán y Cocibolca (Weyl, 1980). Weyl (1980) estima que la depresión ha sido rellenada por sedimentos aluviales y materiales volcánicos que alcanzan un espesor de 2,000 m, lo cual ha causado cambios en la estructura del lago hasta llegar a los $31 \mathrm{msnm}$ y a una profundidad promedio de $13 \mathrm{~m}$ (Vammen et al., 2006).

Gillespie (1994) sugiere que el aislamiento pudo finalizar hace 10,000 años, lo que restringió el flujo de fauna y definió la biota de la isla al establecerse una brecha acuática; aunque la información disponible no permite estimar cuantas especies de mamíferos llegaron habitar la isla antes del cierre definitivo, no podemos eximir como probables habitantes históricos a ninguna especie típicamente distribuida en el pacífico sur de Nicaragua que debieron tener las mismas oportunidades. Por su parte, tampoco es posible saber cuántas especies coexistían cuando llegaron los humanos en el año 4000 a.C., quienes han cambiado el paisaje de la isla (Haberland, 1992).

Los primeros humanos en Ometepe fueron chibchas suramericanos, posiblemente matagalpas o mayangnas (Lothrop, 1998); restos de conchas de tortuga y huesos de venado, armadillos y guatusas de hace 2,000 años son atribuidas a estas etnias (Healy, 1980). Un segundo grupo llegó en el año 800 , con la llegada de los chorotegas provenientes de México, seguido por nicaraos en el año 1200 (Baker, 2013). Baker (2013) estima que los nicaraos ocupaban el occidente de la isla, los chorotegas el noreste y los descendientes chibchas habitaban el volcán Maderas. Lo poco que sabemos sobre la convivencia de estos grupos en la isla fue dado a conocer por los conquistadores del siglo XVI, quienes describieron aspectos cotidianos como la ca- 
cería, al interpretar dibujos pictográficos plasmados en pieles de venado (Serra-Vázquez, 2015).

El descubrimiento del desaguadero de la mar dulce en 1539 que conectó el Pacífico y el Caribe, estableció una ruta de tránsito que involucraría a Ometepe como un sitio de abastecimiento de provisiones y refugio, no solo de españoles sino también de piratas, exploradores y naturalistas (Serra-Vázquez, 2015). Ritter von Friedrichsthal en 1837, Frederick Boyle en 1863 y Pablo Levy en 1869, realizaron los primeros estudios sobre geografía, zoología y geología respectivamente (Boyle, 1868; Houwald, 1975; Levy, 1873). Estas exploraciones dieron como resultado la primera reseña mastozoológica del lago Cocibolca, la cual incluía al primate Mycetes palliatus Gray 1849 (= Alouatta palliata), que fue incorporado en la Biologia Centrali Americana de la Sociedad Linneana (Alston, 1882). En 1883 nuevos reportes de fauna se dieron en la isla por el biólogo sueco Carl Bovallius, quien colectó para la Universidad de Upsala Suecia (uus) nueve especies de mamíferos (Bovallius, 1977).

Los estudios en Ometepe continuaron en los años cincuenta y sesenta del siglo XX con J. KnoX Jones Jr. y la Universidad de Kansas (UK), quienes colectaron más de 500 mamíferos (Jones Jr. y Phillips, 1969). A finales del siglo XX se realizó el Ordenamiento Territorial de Ometepe, que incluyó un listado de las especies mastozoológicas (FUNDENIC, 1994). No obstante, el establecimiento de una estación biológica en el volcán Maderas acrecentó los estudios biológicos, tanto florísticos (Gillespie, 1994; Gillespie y Prigge, 1997) como de fauna, incluidos importantes inventarios de mamíferos realizados por Neal Woodman y la Universidad de Pennsylvania (Woodman, 1998; 2002), y Vilchez (2005) quien inventarió los mamíferos como insumo para el plan de manejo de la Reserva. Por su parte, continuaron evaluaciones de primates (Garber et al., 1999; McCann et al., 2003; Williams-Guillén et al., 2006) y estimación poblacional del venado Odocoileus virginianus (Rodríguez, 2009). Por último se analizan los resultados del estudio mastozoológico de la isla de Ometepe como insumos para la propuesta de biosfera (Medina, 2010).

\section{Área de Estudio}

La isla de Ometepe de $276 \mathrm{~km}^{2}$ está ubicada en el lago Cocibolca, un lago de agua dulce de $8,264 \mathrm{~km}^{2}$ con 400 isletas, dos islas y dos volcanes. El volcán
Concepción (1,610 m), al oeste de la isla, se encuentra activo y tiene vegetación escasa, mientras que el volcán Maderas al oriente (1,430 m), se compone de un cono truncado y una laguna de cuatro ha alimentada por la condensación de la humedad del bosque nuboso (INETER, 1994). La isla pertenece al departamento de Rivas y se divide en dos municipios: Moyogalpa y Altagracia; con una población de 40,000 habitantes. Presenta un régimen lluvioso de mayo a noviembre, con un promedio de $1,600 \mathrm{~mm}$ anuales y una temperatura media de $27^{\circ} \mathrm{C}$ (INETER, 1994).

Ometepe tiene una combinación de climas; los sectores de Altagracia y el Volcán Maderas son influidos por flujos húmedos del Caribe, que afecta a la vegetación y crea mayor precipitación, lo cual forma ecosistemas típicos de trópico húmedo. Moyogalpa y las zonas bajas de ambos volcanes que reciben menos humedad producen ecosistemas de trópico seco (Gillespie, 1994). Díaz y Díaz (2009) determinaron que hay seis ecosistemas: bosque nuboso, bosque húmedo, transición bosque húmedo-seco, boque seco, coladas volcánicas y humedales (Figura 2). La isla fue declarada área protegida en 1983 bajo decreto 1320 , donde se reconocen a ambos volcanes como reservas naturales y por la ley 203 en 1995 que la declaró Patrimonio Cultural de la Nación (La Gaceta, 2013). La Organización de las Naciones Unidas para la Educación, la Ciencia y la Cultura (UNESCO) la integró en 2010 al Programa Hombre y Biósfera, la cual fue aprobada bajo Ley No. 833 en La Gaceta (2013) con tres áreas protegidas: La Reserva Natural Volcán Concepción (Figura 3), El Parque Nacional Volcán Maderas (Figura 4) y El Refugio de Vida Silvestre Peña Inculta-Humedal Istián (Figura 5).

\section{MÉTOdos}

Para hacer esta investigación, se realizó una exhaustiva revisión bibliográfica y análisis de información no publicada científicamente, que incluye reportes técnicos y tesis, los cuales se tabulan cronológicamente en tiempo y espacio. No se revisó el material depositado en museos extranjeros pertinente a los mamíferos de la isla, aunque sí se revisaron las bases de datos de murciélagos y roedores de Ometepe de la University of Kansas Biodiversity Research Center (UK) y del American Museum of Natural History (AMNH). La nomenclatura se basó en Wilson y Reeder (2005), con cambios acordes a publicaciones recientes. 

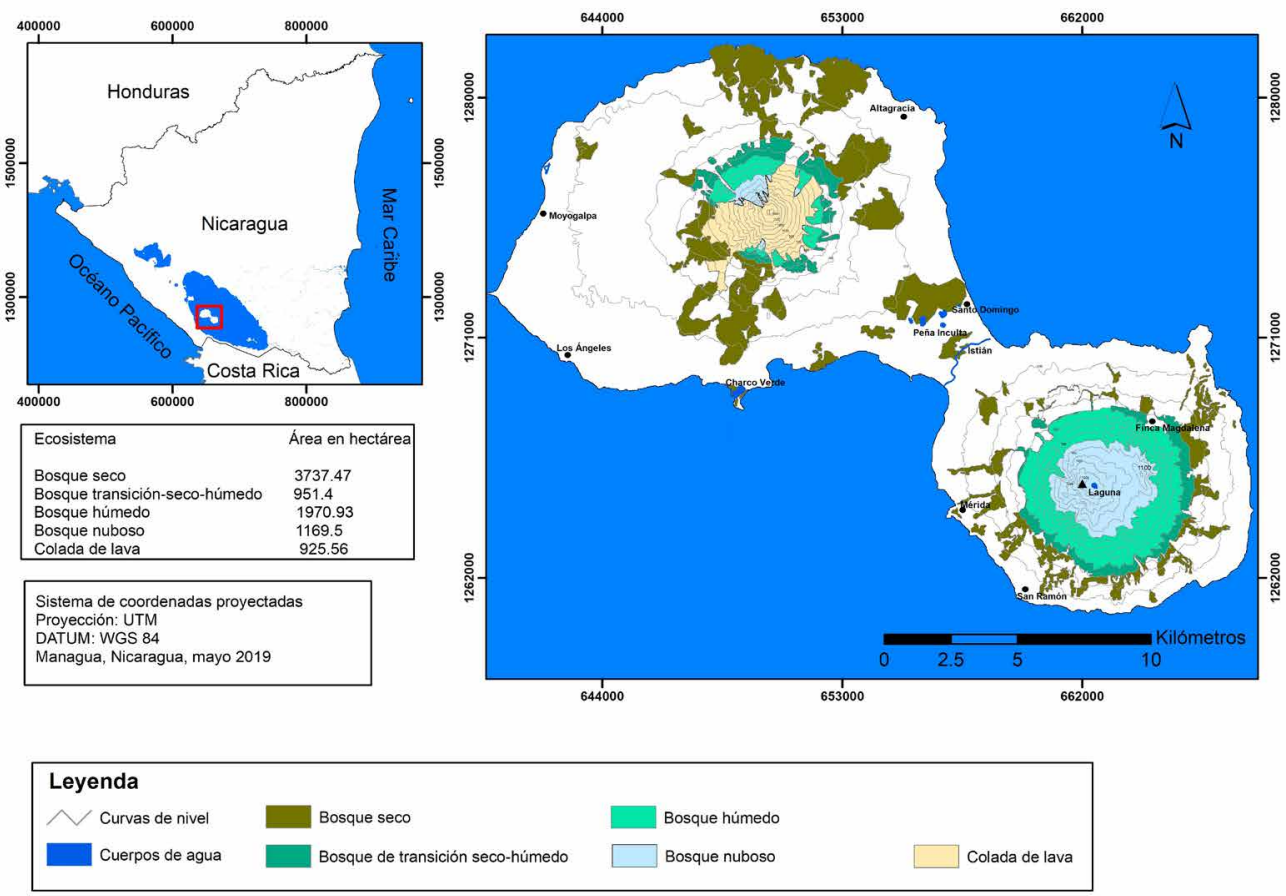

Figura 2. Diferentes tipos de ecosistemas que se presentan en la isla de Ometepe, Nicaragua. Tomado de Díaz y Díaz, 2009.

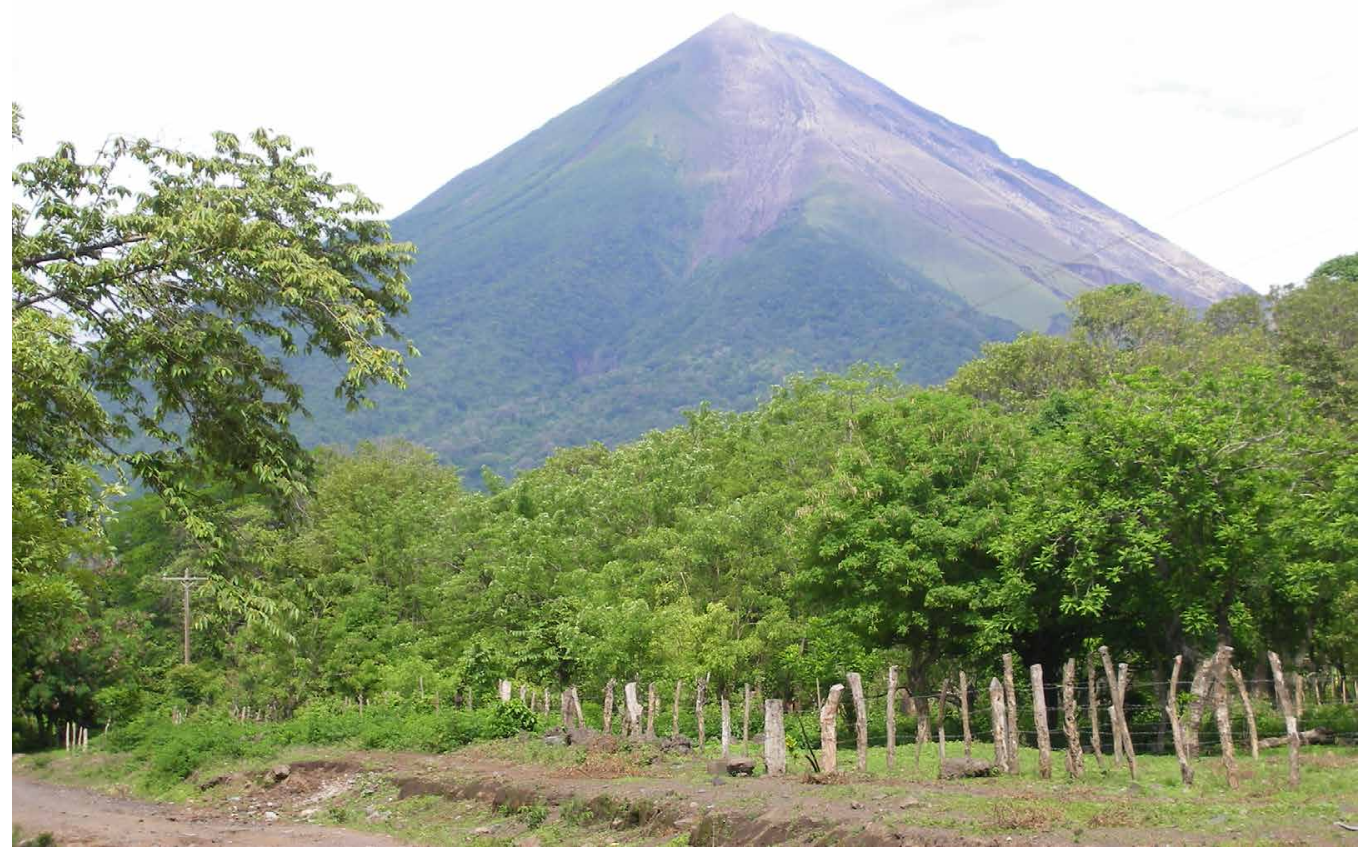

Figura 3. Reserva Natural Volcán Concepción en la Isla de Ometepe en Nicaragua. Foto: Arnulfo Medina. 


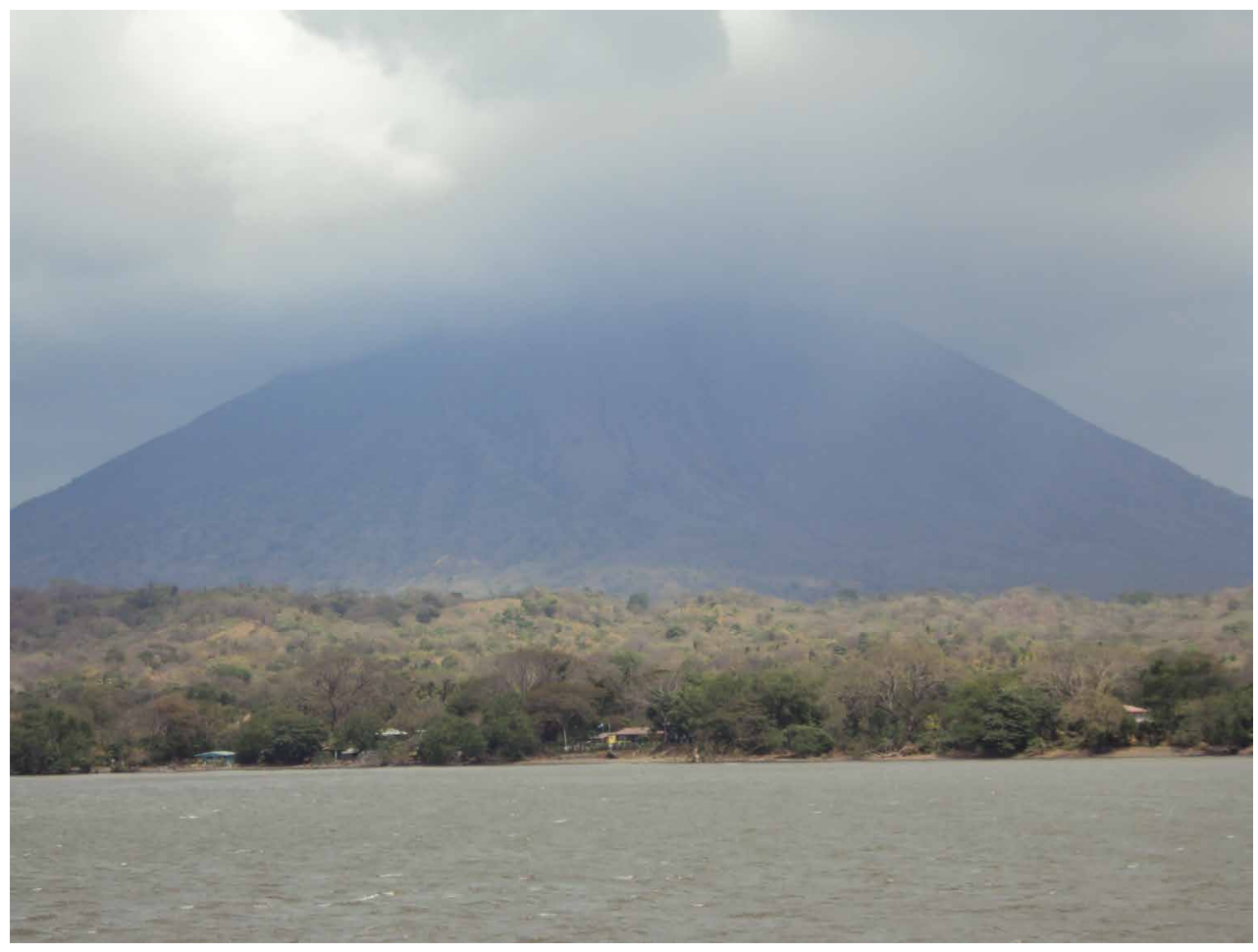

Figura 4. Parque Nacional Volcán Maderas, Isla Ometepe en Nicaragua. Foto: Arnulfo Medina.

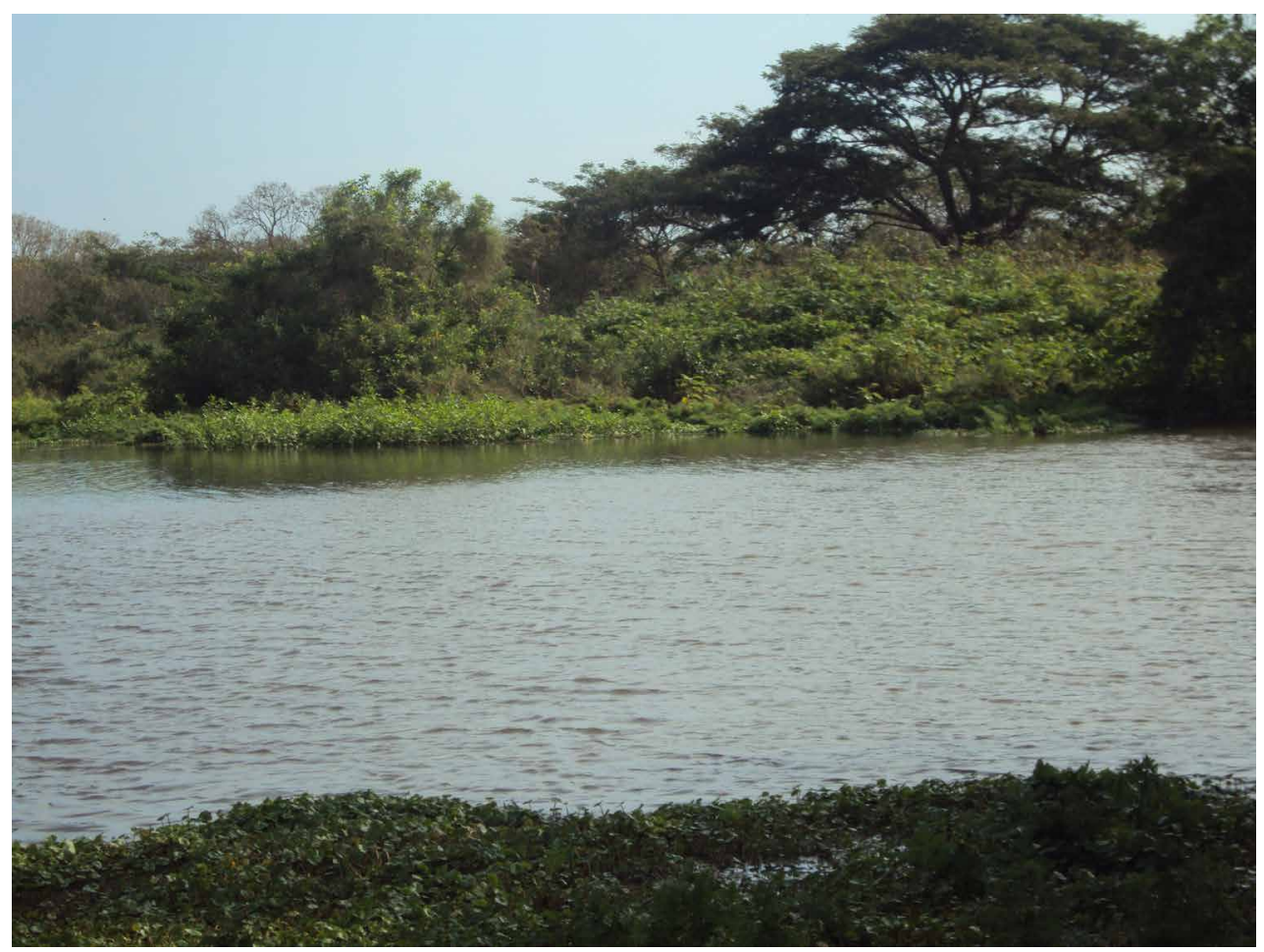

Figura 5. Refugio Vida Silvestre Peña Inculta-Humedal Istián, Isla Ometepe, Nicaragua. Foto: Arnulfo Medina. 
Todas las localidades expresadas en las distribuciones de las especies se encuentran en el mapa de ecosistemas de la isla (Figura 2).

\section{Resultados}

Como resultado se reconocen 9 ordenes, 17 familias y 51 especies de mamíferos en la isla de Ometepe (Cuadro 1), lo que representa el $26.4 \%$ del total de mamíferos continentales de Nicaragua (Medina-Fitoria y Saldaña, 2012). Esto incluye seis especies sin reportes científicos previos: Lampronycteris brachyotis, Lonchorhina aurita, Micronycteris microtis, Trinycteris nicefori, Chrotopterus auritus y Natalus mexicanus. Esta diversidad también contiene dos especies no nativas, la rata (Rattus rattus) y el ratón común (Mus musculus) y se evidencia la extinción de la especie de primate Ateles geoffroyi.

Cuadro 1. Lista de especies de mamíferos y las tres áreas protegidas (Volcán Concepción, Istían Peña Inculta y Volcán Maderas) en la isla de Ometepe, Nicaragua.

\begin{tabular}{|c|c|c|c|c|}
\hline $\mathrm{N}^{\mathrm{o}}$ & Orden / Familia / Especie & Volcán Concepción & $\begin{array}{c}\text { Istián } \\
\text { (Peña Inculta) }\end{array}$ & Volcán Maderas \\
\hline \multicolumn{5}{|c|}{ Marsupialia / Didelphidae } \\
\hline 1 & Philander opossum & $\begin{array}{c}\text { Bosque seco } \\
\text { (Medina, 2010) }\end{array}$ & & $\begin{array}{c}\text { La Laguna (Vílchez, 2005; } \\
\text { Medina, 2010) } \\
\text { San Ramón } \\
\text { (Woodman, 1998) }\end{array}$ \\
\hline 2 & Didelphis marsupialis & & $\begin{array}{l}\text { Humedal Iztian } \\
\text { (Medina, 2010) }\end{array}$ & $\begin{array}{c}\text { San Ramón } \\
\text { (Woodman, 1998) }\end{array}$ \\
\hline \multicolumn{5}{|c|}{ Cingulata / Dasypodidae } \\
\hline 3 & Dasypus novemcinctus & $\begin{array}{c}\text { Moyogalpa } \\
\text { (Bovallius, 1977) } \\
\text { Bosque seco } \\
\text { (Medina, 2010) }\end{array}$ & & $\begin{array}{l}\text { Bosque húmedo } \\
\text { (Vílchez, 2005) }\end{array}$ \\
\hline 4 & Cabassous centralis & & & $\begin{array}{c}\text { San Ramón } \\
\text { (Woodman, 1998) }\end{array}$ \\
\hline \multicolumn{5}{|c|}{ Pilosa / Myrmecophagidae } \\
\hline 5 & Tamandua mexicana & $\begin{array}{c}\text { Moyogalpa } \\
\text { (Bovallius, 1977) }\end{array}$ & & $\begin{array}{c}\text { San Ramón } \\
\text { (Woodman, 1998) } \\
\text { Bosque húmedo } \\
\text { (Medina, 2010) }\end{array}$ \\
\hline \multicolumn{5}{|c|}{ Chiroptera / Emballonuridae } \\
\hline 6 & Rhynchonycteris naso & $\begin{array}{c}\text { Altagracia } \\
\text { (Base datos UK) }\end{array}$ & $\begin{array}{c}\text { Peña Inculta } \\
\text { (Woodman, 1998) } \\
\text { Humedal Istián } \\
\text { (Medina, 2010) }\end{array}$ & $\begin{array}{l}\text { Bosque seco } \\
\text { (Vílchez, 2005) }\end{array}$ \\
\hline 7 & Balantiopteryx plicata & $\begin{array}{c}\text { Altagracia } \\
\text { (Base datos UK) }\end{array}$ & $\begin{array}{l}\text { Santo Domingo } \\
\text { (Base datos UK) }\end{array}$ & $\begin{array}{c}\text { San Ramón } \\
\text { (Woodman, 1998) }\end{array}$ \\
\hline 8 & Saccopteryx bilineata & $\begin{array}{c}\text { Altagracia } \\
\text { (Base datos UK) } \\
\text { Bosque seco } \\
\text { (Medina, 2010) }\end{array}$ & & $\begin{array}{c}\text { San Ramón } \\
\text { (Woodman, 1998) }\end{array}$ \\
\hline
\end{tabular}


Cuadro 1. Continuación...

\begin{tabular}{|c|c|c|c|c|}
\hline $\mathrm{N}^{\mathrm{o}}$ & Orden / Familia / Especie & Volcán Concepción & $\begin{array}{c}\text { Istián } \\
\text { (Peña Inculta) }\end{array}$ & Volcán Maderas \\
\hline \multicolumn{5}{|c|}{ Noctilionidae } \\
\hline 9 & Noctilio albiventris & $\begin{array}{c}\text { Altagracia } \\
\text { (Base datos UK) }\end{array}$ & $\begin{array}{l}\text { Humedal Istián } \\
\text { (Medina, 2010) }\end{array}$ & $\begin{array}{c}\text { San Ramón } \\
\text { (Woodman, 1998) }\end{array}$ \\
\hline 10 & Noctilio leporinus & $\begin{array}{c}\text { Altagracia } \\
\text { (Jones Jr. et al., 1971) }\end{array}$ & & $\begin{array}{c}\text { Merida } \\
\text { (Jones Jr. et al., 1971) } \\
\text { San Ramón } \\
\text { (Woodman, 1998) }\end{array}$ \\
\hline \multicolumn{5}{|c|}{ Phyllostomidae } \\
\hline 11 & Lampronycteris brachyotis & $\begin{array}{c}\text { Bosque seco } \\
\text { (Medina, 2010) }\end{array}$ & & \\
\hline 12 & Lonchorhina aurita & $\begin{array}{c}\text { Bosque seco } \\
\text { (Medina, 2010) }\end{array}$ & & \\
\hline 13 & Phyllostomus discolor & $\begin{array}{c}\text { Moyogalpa } \\
\text { (Base de datos UK) } \\
\text { Bosque seco } \\
\text { (Medina, 2010) }\end{array}$ & $\begin{array}{c}\text { Santo Domingo } \\
\text { (Base datos UK) } \\
\text { Peña Inculta } \\
\text { (Woodman, 1998) }\end{array}$ & \\
\hline 14 & Micronycteris microtis & & & $\begin{array}{l}\text { Finca Magdalena } \\
\text { (Vílchez, 2005) }\end{array}$ \\
\hline 15 & Trinycteris nicefori & & & $\begin{array}{l}\text { Finca Magdalena } \\
\text { (Vílchez, 2005) }\end{array}$ \\
\hline 16 & Chrotopterus auritus & & & $\begin{array}{l}\text { Bosque nuboso } \\
\text { (Vílchez, 2005) }\end{array}$ \\
\hline 17 & Glossophaga comissarisi & $\begin{array}{c}\text { Bosque seco } \\
\text { (Medina, 2010) }\end{array}$ & $\begin{array}{c}\text { Peña Inculta } \\
\text { (Medina, 2010) }\end{array}$ & $\begin{array}{l}\text { Bosque seco y nuboso } \\
\text { (Vílchez, 2005) }\end{array}$ \\
\hline 18 & Glossophaga soricina & $\begin{array}{c}\text { Moyogalpa } \\
\text { (Base de datos UK) } \\
\text { Bosque seco } \\
\text { (Medina, 2010) }\end{array}$ & $\begin{array}{c}\text { Santo Domingo } \\
\text { (Base de datos UK) } \\
\text { Peña Inculta } \\
\text { (Medina, 2010) }\end{array}$ & $\begin{array}{c}\text { Mérida } \\
\text { (Base de datos UK) } \\
\text { Bosque seco } \\
\text { (Vílchez, 2005) }\end{array}$ \\
\hline 19 & Glossophaga leachii & $\begin{array}{c}\text { Moyogalpa } \\
\text { (Base de datos UK) }\end{array}$ & & $\begin{array}{c}\text { San Ramón } \\
\text { (Woodman, 1998) }\end{array}$ \\
\hline 20 & Carollia perspicillata & $\begin{array}{c}\text { Moyogalpa } \\
\text { (Base de datos UK) } \\
\text { Bosque seco } \\
\text { (Medina, 2010) }\end{array}$ & $\begin{array}{c}\text { Peña Inculta } \\
\text { (Woodman, 1998) } \\
\text { Humedal Istián } \\
\text { (Medina, 2010) }\end{array}$ & $\begin{array}{l}\text { Bosque seco y Húmedo } \\
\text { (Vílchez, 2005) } \\
\text { Bosque seco y Húmedo } \\
\text { (Medina, 2010) }\end{array}$ \\
\hline 21 & Carollia subrufa & $\begin{array}{c}\text { Moyogalpa } \\
\text { (Base de datos UK) } \\
\text { Bosque seco } \\
\text { (Medina, 2010) }\end{array}$ & $\begin{array}{c}\text { Peña Inculta } \\
\text { (Woodman, 1998) }\end{array}$ & $\begin{array}{c}\text { Mérida } \\
\text { (Base de datos UK) } \\
\text { Bosque seco (Vílchez, } \\
\text { 2005; Medina, 2010) }\end{array}$ \\
\hline 22 & Carollia sowelli & & & $\begin{array}{c}\text { Mérida } \\
\text { (Base de datos UK) } \\
\text { San Ramón } \\
\text { (Woodman, 1998) }\end{array}$ \\
\hline
\end{tabular}




\section{Cuadro 1. Continuación...}

\begin{tabular}{|c|c|c|c|c|}
\hline $\mathrm{N}^{\circ}$ & Orden / Familia / Especie & Volcán Concepción & $\begin{array}{c}\text { Istián } \\
\text { (Peña Inculta) }\end{array}$ & Volcán Maderas \\
\hline 23 & Sturnira parvidens & $\begin{array}{c}\text { Moyogalpa } \\
\text { (Base de datos UK) } \\
\text { Bosque seco } \\
\text { (Medina, 2010) }\end{array}$ & $\begin{array}{c}\text { Peña Inculta } \\
\text { (Woodman, 1998) }\end{array}$ & $\begin{array}{c}\text { Mérida } \\
\text { (Base de datos UK) }\end{array}$ \\
\hline 24 & Artibeus jamaicensis & $\begin{array}{c}\text { Moyogalpa y Altagracia } \\
\text { (Base de datos UK) } \\
\text { Bosque seco } \\
\text { (Medina, 2010) }\end{array}$ & & $\begin{array}{l}\text { Bosque seco y húmedo } \\
\text { (Vílchez, 2005) } \\
\text { Bosque seco y húmedo } \\
\text { (Medina, 2010) }\end{array}$ \\
\hline 25 & Artibeus lituratus & $\begin{array}{c}\text { Altagracia } \\
\text { (Base datos UK) }\end{array}$ & & $\begin{array}{c}\text { San Ramón } \\
\text { (Woodman, 1998) } \\
\text { Bosque seco y húmedo } \\
\text { (Medina, 2010) }\end{array}$ \\
\hline 26 & Dermanura phaeotis & & $\begin{array}{c}\text { Peña Inculta } \\
\text { (Base de datos UK) } \\
\text { Humedal Istián } \\
\text { (Medina, 2010) }\end{array}$ & $\begin{array}{c}\text { Bosque seco } \\
\text { (Vílchez, 2005) }\end{array}$ \\
\hline 27 & Dermanura watsoni & & & $\begin{array}{c}\text { San Ramón } \\
\text { (Woodman, 1998) }\end{array}$ \\
\hline 28 & Dermanura tolteca & & & $\begin{array}{c}\text { Mérida y San Ramón } \\
\text { (Jones Jr. et al., 1971) } \\
\text { San Ramón } \\
\text { (Woodman, 1998) } \\
\text { Bosque húmedo } \\
\text { (Medina 2010) }\end{array}$ \\
\hline 29 & Uroderma convexum & $\begin{array}{c}\text { Altagracia } \\
\text { (Base de datos UK) }\end{array}$ & $\begin{array}{l}\text { Humedal Istián } \\
\text { (Medina, 2010) }\end{array}$ & $\begin{array}{l}\text { Finca Magdalena } \\
\text { (Vílchez, 2005) }\end{array}$ \\
\hline 30 & Platyrrhinus helleri & $\begin{array}{c}\text { Bosque seco } \\
\text { (Medina, 2010) }\end{array}$ & $\begin{array}{c}\text { Sto.Domingo } \\
\text { (Base de datos UK) }\end{array}$ & $\begin{array}{c}\text { Mérida y San Ramón } \\
\text { (Jones Jr. et al., 1971) } \\
\text { Finca Magdalena } \\
\text { (Vílchez, 2005) }\end{array}$ \\
\hline 31 & Chiroderma villosum & $\begin{array}{c}\text { Bosque seco } \\
\text { (Medina, 2010) }\end{array}$ & $\begin{array}{c}\text { Sto.Domingo } \\
\text { (Base de datos UK) } \\
\text { Peña Inculta } \\
\text { (Woodman, 1998) }\end{array}$ & $\begin{array}{c}\text { Mérida } \\
\text { (Jones Jr. et al., 1971) }\end{array}$ \\
\hline 32 & Desmodus rotundus & $\begin{array}{c}\text { Altagracia } \\
\text { (Base de datos UK) }\end{array}$ & $\begin{array}{c}\text { Peña Inculta } \\
\text { (Woodman, 1998) }\end{array}$ & $\begin{array}{c}\text { Mérida } \\
\text { (Jones Jr. et al., 1971) } \\
\text { San Ramón } \\
\text { (Woodman, 1998) } \\
\text { Bosque seco } \\
\text { (Vílchez, 2005) }\end{array}$ \\
\hline \multicolumn{5}{|c|}{ Natalidae } \\
\hline 33 & Natalus mexicanus & & & $\begin{array}{l}\text { Bosque seco } \\
\text { (Vílchez, 2005) }\end{array}$ \\
\hline
\end{tabular}


Cuadro 1. Continuación...

\begin{tabular}{|c|c|c|c|c|}
\hline $\mathrm{N}^{\mathrm{o}}$ & Orden / Familia / Especie & Volcán Concepción & $\begin{array}{c}\text { Istián } \\
\text { (Peña Inculta) }\end{array}$ & Volcán Maderas \\
\hline \multicolumn{5}{|c|}{ Vespertilionidae } \\
\hline 34 & Rhogeessa bickhami & $\begin{array}{c}\text { Bosque seco } \\
\text { (Medina, 2010) }\end{array}$ & $\begin{array}{c}\text { Sto.Domingo } \\
\text { (Base de datos UK) } \\
\text { Peña Inculta } \\
\text { (Woodman, 1998) }\end{array}$ & $\begin{array}{c}\text { San Ramón } \\
\text { (Base de datos UK) }\end{array}$ \\
\hline \multicolumn{5}{|c|}{ Primates / Cebidae } \\
\hline 35 & Cebus capucinus & $\begin{array}{c}\text { Charco Verde } \\
\text { (Bovallius, 1977) }\end{array}$ & & $\begin{array}{c}\text { Nebliselva } \\
\text { (Woodman, 1998) } \\
\text { Finca Magdalena } \\
\text { (Medina, 2010) }\end{array}$ \\
\hline 36 & Alouatta palliata & $\begin{array}{c}\text { Moyogalpa } \\
\text { (Boyle, 1868) } \\
\text { Moyogalpa } \\
\text { (Bovallius, 1977) } \\
\text { Bosque seco } \\
\text { (Woodman, 1998) } \\
\text { Charco Verde } \\
\text { (Medina, 2010) }\end{array}$ & $\begin{array}{c}\text { Humedal } \\
\text { (Medina, 2010) }\end{array}$ & $\begin{array}{l}\text { Bosque seco y húmedo } \\
\text { (Garber et al., 1999) } \\
\text { Bosque seco y húmedo } \\
\text { (McCann et al. 2003) } \\
\text { Cafetal } \\
\text { (Williams-Guillén et al } \\
\text { 2006) }\end{array}$ \\
\hline+ & Ateles geoffroyi & $\begin{array}{c}\text { Moyogalpa } \\
\text { (Bovallius, 1977) }\end{array}$ & & \\
\hline
\end{tabular}

\section{Sciurus variegatoides}

\author{
Moyogalpa \\ (Boyle, 1868) \\ Jones Jr. y Phillips, 1969 \\ Bosque seco \\ (Medina, 2010)
}

Peña Inculta (Woodman, 1998)

Humedal (Medina, 2010)
Jones Jr. y Phillips, 1969

San Ramón (Vílchez, 2005;

Woodman, 1998)

Bosque seco (Medina, 2010)

\begin{tabular}{|c|c|c|c|c|}
\hline \multicolumn{5}{|c|}{ Heteromyidae } \\
\hline 38 & Liomys salvini & $\begin{array}{c}\text { Altagracia } \\
\text { (Genoways, 1973) } \\
\text { Bosque seco } \\
\text { (Medina, 2010; } \\
\text { Woodman, 2002) }\end{array}$ & $\begin{array}{c}\text { Peña Inculta } \\
\text { (Woodman, 1998) }\end{array}$ & $\begin{array}{c}\text { Mérida } \\
\text { (Genoways, 1973) }\end{array}$ \\
\hline \multicolumn{5}{|c|}{ Cricetidae } \\
\hline 39 & Sigmodon hirsutus & & $\begin{array}{c}\text { Peña Inculta } \\
\text { (Woodman, 2002) }\end{array}$ & $\begin{array}{l}\text { Bosque húmedo } \\
\text { (Vílchez, 2005) } \\
\text { Bosque nuboso } \\
\text { (Medina, 2010) }\end{array}$ \\
\hline 40 & Oryzomys couesi & $\begin{array}{c}\text { Altagracia } \\
\text { (Jones Jr. } \\
\text { y Engstrom, 1986) }\end{array}$ & & $\begin{array}{c}\text { San Ramón } \\
\text { (Woodman, 1998) }\end{array}$ \\
\hline 41 & Oligoryzomys fulvescens & $\begin{array}{c}\text { Altagracia } \\
\text { (Jones Jr. } \\
\text { y Engstrom, 1986) }\end{array}$ & & $\begin{array}{c}\text { San Ramón } \\
\text { (Woodman, 1998) }\end{array}$ \\
\hline
\end{tabular}


Cuadro 1. Continuación...

\begin{tabular}{|c|c|c|c|c|}
\hline $\mathrm{N}^{\circ}$ & Orden / Familia / Especie & Volcán Concepción & $\begin{array}{c}\text { Istián } \\
\text { (Peña Inculta) }\end{array}$ & Volcán Maderas \\
\hline 42 & Peromyscus mexicanus & & & $\begin{array}{c}\text { Mérida } \\
\text { (Jones Jr y Yates 1983) } \\
\text { San Ramón } \\
\text { (Woodman, 1998) } \\
\text { Bosque húmedo y nuboso } \\
\text { (Medina, 2010; } \\
\text { Vílchez, 2005) }\end{array}$ \\
\hline \multirow[t]{2}{*}{43} & Peromyscus stirtoni & $\begin{array}{c}\text { Bosque seco } \\
\text { (Medina, 2010) }\end{array}$ & $\begin{array}{c}\text { Peña Inculta } \\
\text { (Woodman, 2002) }\end{array}$ & \\
\hline & Muridae & & & \\
\hline 44 & Rattus rattus & $\begin{array}{c}\text { Altagracia } \\
\text { (Medina, 2010) }\end{array}$ & & $\begin{array}{c}\text { San Ramón } \\
\text { (Woodman, 1998) }\end{array}$ \\
\hline \multirow[t]{2}{*}{45} & Mus musculus & & $\begin{array}{l}\text { Santo Domingo } \\
\text { (Medina, 2010) }\end{array}$ & $\begin{array}{c}\text { San Ramón } \\
\text { (Woodman, 1998) }\end{array}$ \\
\hline & Erethizontidae & & & \\
\hline \multirow[t]{2}{*}{46} & Sphiggurus mexicanus & $\begin{array}{c}\text { Moyogalpa } \\
\text { (Bovallius, 1977) }\end{array}$ & $\begin{array}{c}\text { Peña Inculta } \\
\text { (Medina, 2010) }\end{array}$ & $\begin{array}{c}\text { San Ramón } \\
\text { (Woodman, 1998) }\end{array}$ \\
\hline & Dasyproctidae & & & \\
\hline \multirow[t]{2}{*}{47} & Dasyprocta punctata & $\begin{array}{c}\text { Moyogalpa } \\
\text { (Bovallius, 1977) } \\
\text { Bosque seco } \\
\text { (Medina, 2010) }\end{array}$ & & $\begin{array}{c}\text { San Ramón } \\
\text { (Woodman, 1998) } \\
\text { Bosque húmedo } \\
\text { (Vílchez, 2005) }\end{array}$ \\
\hline & Lagomorpha / Leporidae & & & \\
\hline 48 & Sylvilagus floridanus & $\begin{array}{c}\text { Moyogalpa } \\
\text { (Bovallius, 1977) } \\
\text { Altagracia } \\
\text { (Yates et al., 1979) }\end{array}$ & $\begin{array}{l}\text { Humedal Istián } \\
\text { (Medina, 2010) }\end{array}$ & $\begin{array}{c}\text { San Ramón } \\
\text { (Woodman, 1998) }\end{array}$ \\
\hline
\end{tabular}

\begin{tabular}{|c|c|c|c|c|}
\hline \multicolumn{5}{|c|}{ Carnívora / Procyonidae } \\
\hline 49 & Nasua narica & & & $\begin{array}{c}\text { San Ramón } \\
\text { (Woodman, 1998) } \\
\text { Bosque seco } \\
\text { (Vílchez, 2005) }\end{array}$ \\
\hline 50 & Procyon lotor & & & $\begin{array}{l}\text { Bosque seco } \\
\text { (Vílchez, 2005) }\end{array}$ \\
\hline \multicolumn{5}{|c|}{ Cetartiodactyla / Cervidae } \\
\hline 51 & Odocoileus virginianus & $\begin{array}{c}\text { Moyogalpa ( } \\
\text { Bovallius, 1977) } \\
\text { Bosque seco } \\
\text { (Jones Jr. y Phillips, 1969) }\end{array}$ & $\begin{array}{c}\text { Peña Inculta } \\
\text { (Woodman, 1998) }\end{array}$ & $\begin{array}{c}\text { San Ramón } \\
\text { (Woodman, 1998) } \\
\text { Bosque húmedo y nuboso } \\
\text { (Rodríguez, 2009) }\end{array}$ \\
\hline
\end{tabular}

† Especie extinta. 
Asimismo, cuatro especies son características del Pacífico seco: el ratón Liomys salvini y los murciélagos Balantiopteryx plicata, Carollia subrufa y Lampronycteris brachyotis; una especie de murciélago es distintiva de las tierras caribeñas, Lonchorhina aurita. El ratón Peromyscus mexicanus y el murciélago Dermanura tolteca son representativos de las montañas altas del norte. Una de estas especies está catalogada con datos deficientes por la Unión Internacional para la Conservación de la naturaleza (IUCN, 2019); dos especies están en riesgo a nivel nacional (Medina-Fitoria et al., 2017); nueve se encuentran en los listados de la Convención sobre el Comercio Internacional de Especies Amenazadas de Fauna y Flora Silvestres-CITES (CCAD, 2010); y 10 están protegidas en Nicaragua por el reglamento de veda del Ministerio del Ambiente y los Recursos Naturales (MARENA, 2016; Cuadro 2).

\section{Análisis de especies relevantes}

\section{Orden Primates (Monos)}

\section{Alouatta palliata (Gray 1849)}

Representa la primera referencia mastozoológica del lago Cocibolca, referida como Mycetes palliatus
(Gray) y descrita en 1848 a partir de supuestos especímenes de Venezuela (Sallé, Museo Británico); sin embargo, P. L. Sclater, Secretario de la Sociedad Zoológica de Londres, demostró que provenían de las islas del lago de Nicaragua (Alston, 1882). En 1863 tres individuos fueron colectados en Ometepe para el Museo Británico (Boyle, 1868) y en 1883 se colectó en Moyogalpa un individuo para la Universidad de Upsala, Suecia-uus (Bovallius, 1977). Este mono habita el bosque seco y húmedo, cafetales y cacaotales de la finca Magdalena del Volcán Maderas (Garber et al., 1999; McCann et al., 2003; Williams-Guillén et al., 2006); así como en el bosque Peña Inculta (Woodman 1998); el bosque seco del Volcán Concepción y en los humedales Charco Verde e Istián (Medina, 2010). Aunque aún es común en la isla, se estima que las metapoblaciones han disminuido, así como sus interacciones y estructuras grupales, aunque aún no presenta evidencia de endogamia (Winkler, 1999).

Ateles geoffroyi (Kuhl, 1820)

Este mono no ha sido reportado desde 1883 cuando C. Bovallius lo describió en Moyogalpa de la siguiente manera:

\section{Cuadro 2. Listado de mamíferos de importancia para la conservación en Ometepe.}

\begin{tabular}{|c|c|c|c|c|}
\hline ESPECIE & $\begin{array}{l}\text { Listas } \\
\text { Rojas }\end{array}$ & CITES & $\begin{array}{c}\text { Vedas } \\
\text { nacionales }\end{array}$ & $\begin{array}{c}\text { Valor } \\
\text { Cinegético }\end{array}$ \\
\hline Lampronycteris brachyotis & PE (Nacional) & & & \\
\hline Trinycteris nicefori & A (Nacional) & & & \\
\hline Tamandua mexicana & & III & Veda Indefinida & \\
\hline Dasypus novemcinctus & & & Veda Parcial & $x$ \\
\hline Cabassous centralis & & III & & \\
\hline Alouatta palliate & & I & Veda Indefinida & \\
\hline Cebus capucinus & & II & Veda Indefinida & \\
\hline Sciurus variegatoides & & & & $X$ \\
\hline Sphiggurus mexicanus & & III & & \\
\hline Dasyprocta punctata & & III & Veda Parcial & $X$ \\
\hline Nasua narica & & III & Veda Parcial & $x$ \\
\hline Odocoileus virginianus & & & Veda Parcial & $x$ \\
\hline Total especies & & 9 & 10 & 5 \\
\hline
\end{tabular}

Listas Rojas= PE: Peligro de extinción, A: amenazada. 


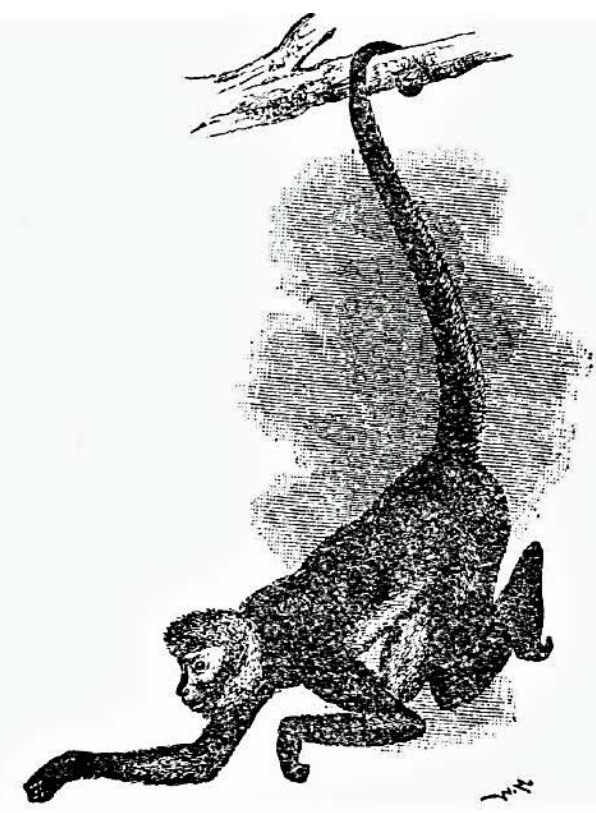

Figura 6. Mono araña (Ateles geoffroyi) en estado silvestre, 1883. Ilustración: Bovallius, 1977.

Una vez me refugié huyendo del sol, oí un alboroto de urracas. Cuando fui a ver me encontré un tropel de monos arañas que estaban robando huevos de los nidos. Desde un árbol tiraban ramas y algunas de las hembras llevaban crías, una por hembra. Un mono saltó a las ramas inferiores y se colgó con la cola en la posición que se representa (Figura 6).

En el poblado Los Ángeles, Bovallius colectó un individuo para la uus (Bovallius, 1977). Nadie más lo ha reportado en estado silvestre, por lo que se considera actualmente extinto. Esto debió ocurrir en la primera mitad del siglo $\mathrm{XX}$ por razones desconocidas, aunque acciones antropogénicas como la cacería de autoconsumo pudo ser una causa, pues según Bovallius (1977) era común en la dieta de los isleños, principalmente de la población indígena.

\section{Orden Rodentia (ardillas, ratas y ratones)}

\section{Sciurus variegatoides (Ogilby, 1839)}

Es una especie mesoamericana con seis subespecies en Nicaragua, una de ellas reconocida en Ometepe como S. v. dorsalis, que es endémica del pacífico de Nicaragua y el noroeste de Costa Rica (Medina-Fitoria et al., 2018). En el siglo XIX, Boyle (1868) y Bovallius (1977) la reportaron en el volcán Concepción. Tres patrones de coloración de esta especie, diferentes a la ya conocida, han sido do- cumentados en la isla (Jones Jr. y Phillips, 1969; Medina-Fitoria et al., 2018). En 1968, J. Jones Jr. describió estas variaciones de la siguiente manera:

Los especímenes del norte de la isla eran inusuales y de hecho representan una subespecie no descrita. Aun así, no estábamos preparados para lo que encontramos. Smith y Choate obtuvieron en el volcán del sur una emocionante muestra, algunas negras, otras canela claro, otras de color rojizo y otras que combinaban amarillo, rojo, negro y blanco (Jones Jr. y Phillips, 1969).

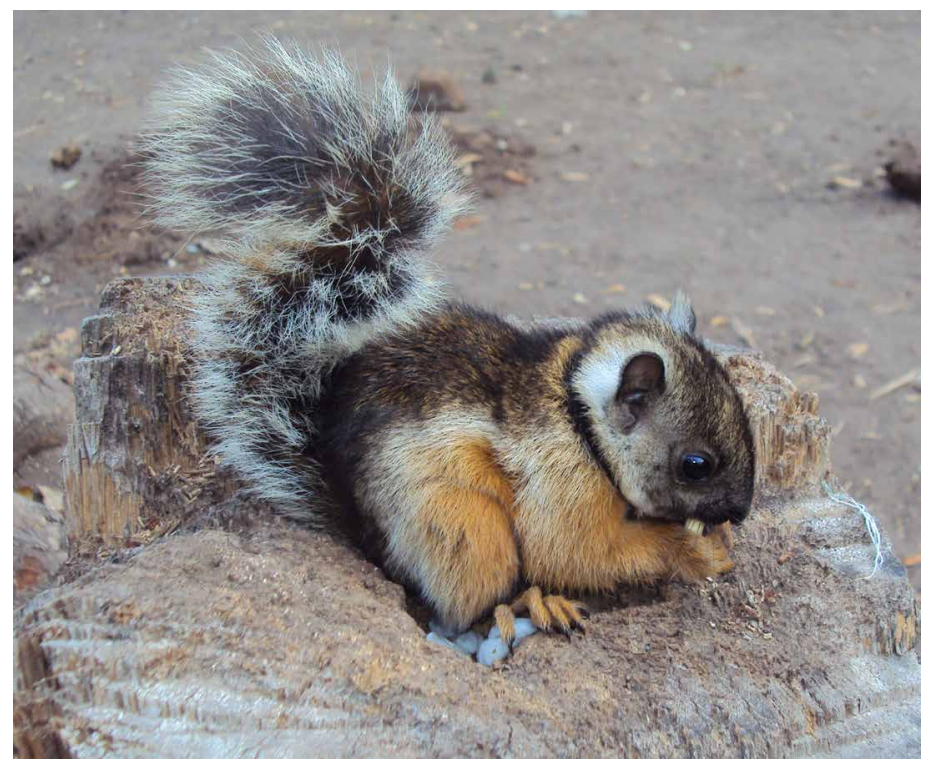

Figura 7. Patrón de coloración no definido taxonómicamente de Sciurus variegatoides, posible intergradación de alguna forma de línea dorsal. Foto: Arnulfo Medina.

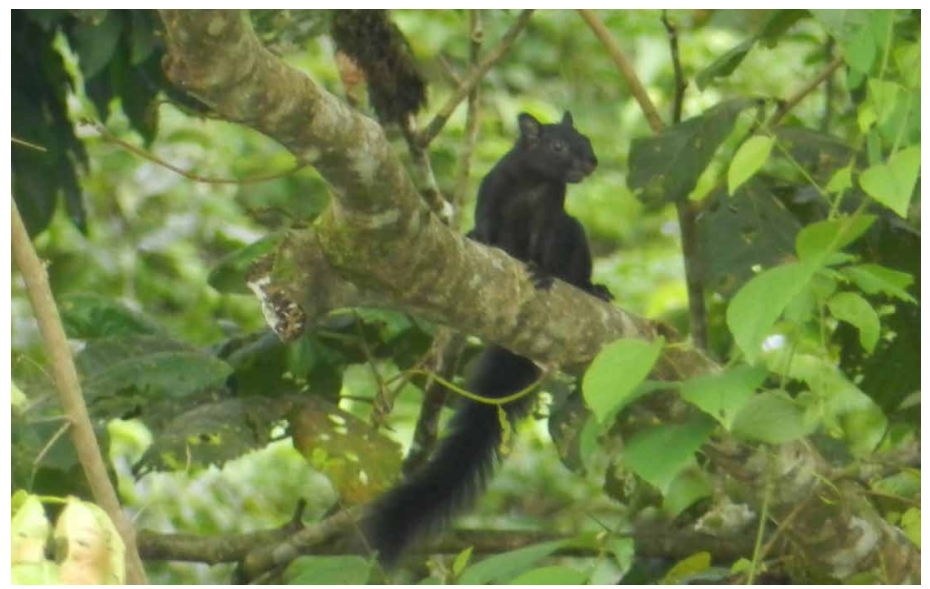

Figura 8. Patrón melánico de $S$. variegatoides. Foto: Orlando Jarquín. 
Aunque estos datos no se han publicado, dos de estos patrones de coloración se han confirmado, uno colorido con líneas laterales (posible variación de alguna subespecie de banda dorsal; Figura 7) y un patrón melánico (Figura 8). La subespecie con banda dorsal, $S$. variegatoides dorsalis habita las partes medias y bajas de ambos volcanes; en las partes bajas del volcán Maderas coexiste con individuos más coloridos y de líneas laterales. No obstante, los individuos melánicos han sido registrados únicamente en el bosque húmedo del volcán Maderas (Medina-Fitoria et al., 2018; Vílchez, 2005; Woodman, 1998).

\section{Liomys salvini (Thomas, 1893)}

Es una especie mesoamericana con dos subespecies en Nicaragua: $L$. S. vulcani del occidente y $L$. s. salvini del pacífico sur y centro del país; la última se encuentra en la isla. Datos de colecta de Altagracia y Moyogalpa (Volcán Concepción) y Mérida (Volcán Maderas) mostraron individuos machos con una longitud más grande que el promedio de la especie y una marcada variación intrapoblacional (Genoways, 1973). En la isla habita los bosques secos $(<300 \mathrm{~m})$ y coladas de lava (Medina, 2010; Woodman, 2002).

\section{Oryzomys couesi (Alston, 1877)}

De acuerdo con colectas del volcán Maderas y Altagracia $(\mathrm{AMNH})$ e identificadas como O. c. couesi, se separaron del grupo de muestras de otras localidades, debido a sus medidas más pequeñas (especialmente de la longitud de la cola), por lo que divergen de vecinos cercanos geográficamente (Jones Jr. y Engstrom, 1986); nuevos reportes en el volcán Maderas (Woodman, 1998).

\section{Peromyscus mexicanus (Saussure, 1860)}

En el volcán Maderas, esta especie ha sido reportada en los cafetales de Mérida (Jones Jr. y Yates, 1983), cultivos de cacao (Medina, 2010) y en los bosques nuboso y húmedo (Vílchez, 2005; Woodman, 1998). Medina (2010) informó de una raza oscura habitando el bosque húmedo y nuboso del volcán Maderas, que coincide con las medidas morfológicas propuestas para esta especie (Figura 9).

Agouti paca (Linnaeus, 1766)

Esta especie fue mencionada en las crónicas de Indias del siglo XIX (Serra-Vázquez, 2015). FUNDENIC

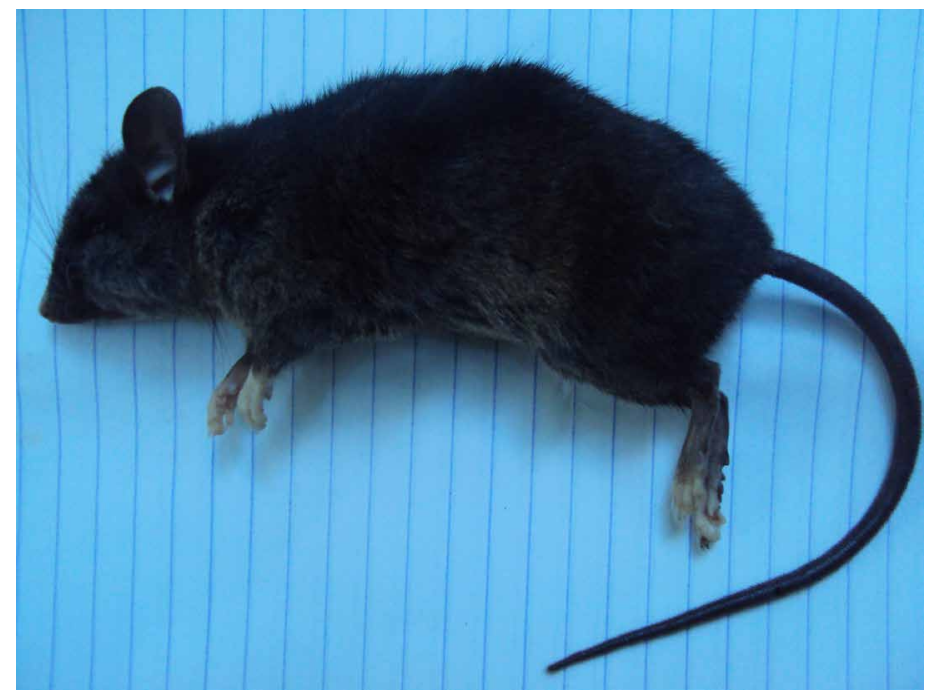

Figura 9. Raza melánica de Peromyscus del Volcán Maderas. Foto: Arnulfo Medina.

(1994) la reportó con base en entrevistas, aunque ningún investigador ha observado esta especie, por lo que su presencia es actualmente incierta.

\section{Orden Carnívora}

En general los carnívoros son escasos en la isla y no hay grandes depredadores. Actualmente, no se encuentran grupos de mamíferos típicos de Nicaragua como felinos, cánidos, mustélidos y mefítidos. Sin embargo, es posible que algunas de estas especies hayan habitado la isla, por lo que se asume la existencia de una antigua conexión. Alusiones al respecto son descritas en la cerámica de Ometepe, donde se muestran abundantes figuras de felinos, por lo cual el periodo que va de 950 a 1100 en la isla se denominó "fase gato" (Serra-Vázquez, 2015). En 1850 Ephraim Squier también hizo referencia a felinos en la isla cuando escribió: Entre los objetos encontrados en Ometepe está una máscara de tigre, en cobre, que no carece de valor artístico y tiene cierto grado de vívido realismo (Squier, 1989). Por último, J. Froebel en su descripción de Ometepe de 1850 también indica la presencia de "tigres" como parte de la fauna típica de la isla (Froebel, 1978). Por su parte, dos especies de mustélidos (Mustela frenata y Eira barbara) son citados por FUNDENIC (1994) con base en entrevistas aun cuando no existe evidencia científica que identifique a estas especies en la isla.

Aunque estos informes no confirman la presencia de grandes carnívoros, no podemos descartar 
su presencia en algún momento histórico de la isla; pero mientras no haya evidencia, estas especies no son consideradas parte de la fauna de Ometepe.

\section{Orden Artiodactyla (venados)}

\section{Odocoileus virginianus (Zimmermann, 1780)}

Los registros de esta especie en la isla datan de hace 2,000 años (Healy, 1980). Fue colectada en 1883 como Cervus rufinus (uus) en el volcán Concepción, Moyogalpa (Bovallius, 1977). Por su parte, en el volcán Maderas fue reportada en el bosque húmedo, en bosque nuboso (Vílchez, 2005; Woodman, 1998), y Rodríguez (2009) la reportó desde los $800 \mathrm{~m}$ hasta la laguna del volcán Maderas (densidad de $0.5 \pm 0.91 \mathrm{EE}$ venados/ha); un valor considerado estable (Gallina, 1994). Según López et al. (2007), esta densidad es posible sin depredadores naturales o cacería. Un ejemplo de ello es la isla San Lucas en Costa Rica, donde se estimó una densidad de 1 individuo/ha. Esta especie requiere estudios poblacionales en el volcán Concepción donde se sospecha que es poco común, así como de estudios genéticos que determinen su relación con otras poblaciones. Jones Jr. y Phillips (1969) observaron que los venados de Ometepe son más pequeños en tamaño que los individuos continentales (Figura 10).

\section{Orden Chiroptera (murciélagos)}

En la isla se reportó una riqueza de 29 especies (Cuadro 1), que representa el $27 \%$ de los murciélagos de Nicaragua (Medina-Fitoria, 2014). Esto incluye 12 especies frugívoras, 10 insectívoras, 3 nectarívoras, 2 carnívoras, 1 especie omnívora y 1 hematófaga. En el mes de abril se han reportado hembras preñadas de las especies Dermanura phaeotis, D. tolteca, Carollia perspicillata, C. subrufa, Glossophaga soricina, L. aurita y Phyllostomus discolor. Un macho activo (escrotado) también fue reportado en esta época, el cual pertenecía a la especie L. brachyotis (Medina, 2010).

\section{Discusión}

La importancia mastozoológica de la isla de Ometepe radica en que en un área relativamente pequeña coexisten actualmente más de una cuarta parte de las especies de mamíferos silvestres del país, de las cuales varias se encuentran en riesgo a nivel nacional. Esta diversidad es producto de procesos

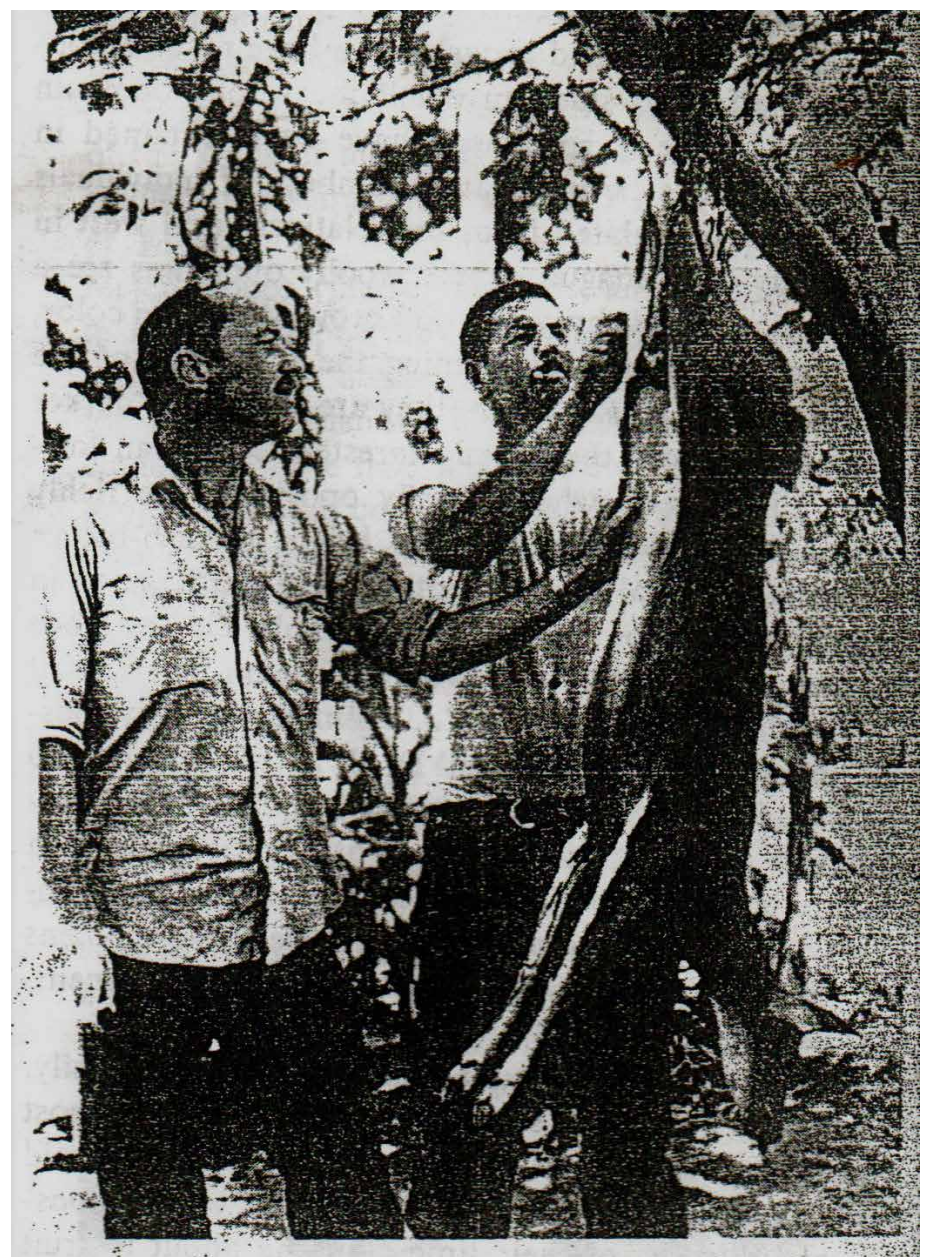

Figure 5. Dr. Jones (left) and James Dale Smith skinning a white-tailed deer from Ometepe. Island. Note the small size of the deer, an adult female, as compared with individuals of the same species from Kansas.

Figura 10. Investigadores de la UK: J. Knox Jones Jr. (izquierda) y James D. Smith desollando un venado en Ometepe. Nota original: nótese el pequeño tamaño, una hembra adulta (Jones Jr. y Phillips, 1969).

evolutivos y antropológicos. Dichos procesos van desde la llegada de las primeras especies de fauna procedentes del norte, seguidos por especies del sur, aunado al aislamiento de estos individuos y la llegada de los humanos. A los humanos se les atribuyen no solo grandes cambios en el paisaje, sino también la extinción de al menos una especie y la introducción de dos especies exóticas que han logrado generar poblaciones silvestres.

Por ser un área de transición entre varias zonas biogeográficas del país, Ometepe presenta una amplia diversidad de ecosistemas terrestres y acuáti- 
cos (Díaz y Díaz, 2009; Gillespie, 1994) y, aunque la mayoría de las especies utilizan varios de estos ecosistemas, algunas están asociadas a un tipo de cobertura específico, por lo que están limitadas a una porción de la isla, por ejemplo especies características del bosque seco, o bien especies del bosque húmedo o de nebliselva. Esto demuestra la importancia de mantener las diferentes coberturas vegetales en su conjunto. Estudios en México (Medellín et al., 2000), Nicaragua (Medina-Fitoria et al., 2007) y Costa Rica (Harvey et al., 2006) han demostrado que al comparar diversos hábitats, la vegetación es la variable más importante para la conservación de especies como los murciélagos en bosques neotropicales.

Los murciélagos son el grupo de mamífero más diverso en Ometepe, ya que agrupa el $57 \%$ de las especies. Su alta riqueza podría asociarse no solo a la alta diversidad de ambientes en la isla, sino también a la capacidad de vuelo que les permite desplazarse grandes distancias (Fleming, 1988), por lo que el viaje de menos de $10 \mathrm{~km}$ que separa a Ometepe del continente no parece ser obstáculo para que los murciélagos se desplacen hacia o fuera de la isla. Medina et al., (2007), a través de recaptura en un paisaje fragmentado de Nicaragua, registraron desplazamientos de $11 \mathrm{~km}$ en especies frugívoras, con registros de hasta $25 \mathrm{~km}$ en el caso de Carollia perspicillata (Fleming, 1988).

No obstante, aunque el aislamiento de Ometepe no parece tener mayor efecto en las comunidades de murciélagos, sí parece haber afectado a algunas especies de mamíferos terrestres por la divergencia en tamaño con poblaciones continentales. Ejemplo de ello son el venado Odocoileus virginianus, cuyas medidas morfológicas son más pequeñas en comparación con individuos del resto del país y de Norteamérica (Jones Jr. y Phillips, 1969), y la rata Oryzomys couesi, la cual también presenta medidas pequeñas, que divergen de los vecinos más cercanos. Según Jones Jr. y Engstrom (1986) podría tratarse de una nueva especie. Foster (1964) y Van Valen (1973) explican con la "regla de islas" cómo las poblaciones isleñas divergen en tamaño en relación con poblaciones continentales, donde especies de cuerpos grandes evolucionan para tener cuerpos de tamaños pequeños (enanismo). La explicación refiere a limitaciones de recursos o para liberarse de la competencia y la depredación que permite la evolución a un tamaño óptimo; el grado de enanismo será proporcional al tiempo de aislamiento (Kirby y
MacFadden, 2005). Este fenómeno ha sido reportado en el pequeño perezoso Bradypus pigmaeus del archipiélago de Bocas del Toro, Panamá (Anderson y Handley, 2002).

También es necesario hacer estudios taxonómicos sobre la ardilla Sciurus variegatoides, que presenta tres patrones diferentes de coloración y solo una es reconocida como subespecie, lo que hace de la isla el único sitio del país donde se ha informado de este tipo de coexistencia (Medina-Fitoria et al., 2018). La simpatría entre tres subespecies de esta especie se da en Costa Rica, entre el golfo de Nicoya y la cordillera de Tilarán, una zona considerada de ecotono (McPherson, 1985). El registro de dos especies de Peromyscus es también un tema sugestivo de investigación, ya que ambas se aíslan de sus rangos de distribución relativamente limitado (Baltensperger y Brown, 2015). Una raza melánica de este género coexiste en el volcán Maderas, la cual se reportó como localmente común en abril de 2010 (Medina, 2010), quizá asociada a P. mexicanus, ya que de acuerdo con Emmons (1999), individuos de esta especie que viven a mayor altura pueden llegar a presentar pelaje más oscuro y denso. Según Álvarez y Cortés (2000) la densidad de roedores en islas puede presentar fuertes fluctuaciones anuales por la disponibilidad de semillas y la densidad de depredadores, de manera que la poca presencia de mamíferos carnívoros podría incidir en la abundancia de roedores.

Aunque especies de mamíferos de gran porte no se presentan actualmente en la isla, como el jaguar (Panthera onca), el puma (Puma concolor), el tapir (Tapirus bairdii) o los chanchos de monte (Tayassuidae), nada impide pensar que no pudieran habitarla. Sin embargo, el pequeño tamaño de la isla pudo condicionar la persistencia de especies con altos requerimientos de hábitat, por lo que algunas de ellas pudieron establecerse con pocos individuos y llegar a extinguirse con solo eliminar algunos de ellos, ya sea por competencia con otras especies silvestres, o bien por causas antropogénicas. Newmark (1995) y MacArthur y Wilson (1967), con su teoría de biogeografía de islas, indican que la proporción de mamíferos en islas disminuye en relación con el tamaño de su superficie y a su distancia al continente, lo cual afecta el índice de extinción y aumenta la posibilidad de extinción en islas pequeñas. Por su parte, el primate Ateles geoffroyi se considera extinto en Ometepe. Aunque reportes de finales del siglo XIX aún describían grupos reproductivos de esta 
especie (Bovallius, 1977), nadie más lo ha reportado en la isla. De manera que si consideramos la extinción como un proceso que ya ha ocurrido en esta zona, es prudente pensar que una mayor cantidad de especies pudo habitar Ometepe, en comparación con la riqueza actual. Aunque pudieron darse extinciones naturales, cabe la posibilidad de que los humanos acrecentaron estos procesos, lo que favoreció el exterminio directo, la disminución del hábitat y la introducción de linajes exóticos. Las especies más vulnerables fueron particularmente las que se movilizan a escalas grandes, como el jaguar, cuyos machos requieren un área de $40 \mathrm{~km}^{2}$ de hábitat (Rabinowitz y Nottingham, 1986) y un área mínima de 5,000 $\mathrm{km}^{2}$ para mantener una población estable (Redford y Robinson, 1991).

Es difícil calcular el costo ambiental causado por los humanos en Ometepe, pero actividades como el cultivo del tabaco del siglo XX tuvieron costos altos por la deforestación para suministro de madera que requerían los hornos de secado. Según Dévé (1985), una manzana (mz) de tabaco (0.7 ha) requería una $\mathrm{mz}$ de bosque, con dos ciclos por año. Esta actividad comenzó en 1950 hasta alcanzar la cifra de 1,500 mz en los años setenta. INETER (1994), señala que en 1990 el bosque denso se redujo a $8 \%$, con $40 \%$ de crecimiento secundario y $45 \%$ agroganadería.

En consecuencia, el hábitat natural disminuyó más del $50 \%$ en una isla, que en proporción ya es pequeña, lo que eliminó casi todos los bosques de bajura y desplazó individuos de zonas costeras a las laderas de los volcanes. Esto también ha disminuido la conexión entre éstos, cuya cintura es el Istmo de Istián, que actualmente concentra buena parte de las tierras cultivables (Baltensperger y Brown, 2015). Según Loiselle y Blake (1991) la ruptura que experimentan los mamíferos en sus rutas de movimiento a nivel local es una de las consecuencias de la fragmentación que más influye en sus poblaciones. Por lo tanto, es de esperarse que en la isla las poblaciones de mamíferos silvestres disminuyan en el futuro sino se toman medidas de protección acorde con los ecosistemas. En principio se debe poner atención a las especies consideradas importantes para la conservación, por lo que es necesario obtener datos poblaciones de muchas especies, ya que sin ellos el establecimiento de prioridades de manejo resulta complejo.

\section{AgradecimiEnTOS}

Agradecemos a Flora y Fauna Internacional (FFI) y a la Fundación entre Volcanes. A Salvadora Morales, Marlon González y Norlan Zambrana. A Timothy McCarthy (q.e.p.d.) y a Bruce Miller, quienes facilitaron mucha de la información histórica de colectas. A Fabricio y Fabio Díaz autores del mapa de Ecosistemas de Ometepe.

\section{LITERATURA CITADA}

Alston E.R. 1882. Mammalia. Pp. 1-220, en: Biologia Centrali-Americana (Godman F. y O. Salvin, eds.) Taylor and Francis, London.

Álvarez S.T. y P. Cortés. 2000. Análisis de la variación de la población de mamíferos pequeños como respuesta a los cambios de la vegetación por el efecto del niño. Centro de Investigaciones Biológicas del Noroeste, S.C. La Paz, B.C.S., México.

Anderson, R.P. y C.O. Handley. 2002. Dwarfism in insular sloths: biogeography, selection, and evolutionary rate. Evolution, 56:1045-1058.

Baltensperger, A. y C. Brown. 2015. Mammalian biodiversity conservation at two biological stations in Nicaragua and Costa Rica. Pp 351-390, en: Central American Biodiversity, conservation and ecology (Huettmann F., ed.). Springer New York.

Baker, S. 2013. El arte rupestre de la isla de Ometepe, Nicaragua: clasificación, cuantificación y comparaciones regionales de motivos. Inédito.

Bloch, J., E. Woodruff, A. Wood y A. Rincon. 2016. First North American fossil monkey and early Miocene tropical biotic interchange. Nature, 533:243-246.

Bovallius, C. 1977. Viaje por Centroamérica 18811883. Trad. C. Vijil. Serie viajeros $N^{\circ} 1$. Fondo promoción Banco de América. Managua D.N. Nicaragua.

Boyle, F. 1868. A Ride Across a Continent: A Personal Narrative of Wanderings Through Nicaragua and Costa Rica. London: Richard Bentley.

CCAD. 2010. Listado actualizado de las especies de flora y fauna incluidos en los apéndices de la CITES, Centroamérica y República Dominicana. USAID/CCAD. 
Cione, A., G. Gasparini, E. Soibelzon, L. Soibelzon, y E. Tonni. 2015. The great American biotic interchange: a South American perspective. SpringerBriefs in Earth System Sciences Series. Springer Netherlands, Dordrecht, Países Bajos.

Dévé, F.C. 1985. La dinámica del sistema agrario frente a la situación energética en la isla de Ometepe. Managua: Proyecto de Cooperación Francia-OEA. Inédito.

Díaz, F. y F. Díaz. 2009. Formaciones vegetales naturales de la isla de Ometepe. Fauna y Flora Internacional, Proyecto Ometepe. Documento técnico inédito.

Emmons, L. 1999. Mamíferos de los Bosques húmedos de América Tropical. Una guía de campo. $1^{a}$ edición en español. Editorial F.A.N. Santa Cruz de la Sierra, Bolivia.

Fleming, T.H. 1988. The short-tailed fruit bat: $A$ study in plant-interactions. The University of Chicago Press, Chicago.

Foster, J. 1964. Evolution of mammals on islands. Nature, 202:234-235.

Froebel, J. 1978. Siete años de viaje en Centro América. Trad. L. Cuadra, Serie Viajeros $N^{\circ} 2$. Managua, Biblioteca Banco de América.

FUNDENIC. 1994. Evaluación del Sistema de Áreas Protegidas de las regiones Pacífico y Centro Norte de Nicaragua. MARENA-Protierra-CBA. Inédito.

Gallina, S. 1994. Uso del hábitat por el venado cola blanca en la Reserva de la Biosfera La Michilía, México, Pp. 299-314, en: Ecología y Manejo del venado cola blanca en México y Costa Rica. (Vaughan, C. y M. Rodríguez, eds.)

Garber, P., J. Pruetz, A. Lavallee y S. Lavallee. 1999. A preliminary study of mantled howling monkey (Alouatta paliatta) ecology and conservation on Isla de Ometepe, Nicaragua. Neotropical Primates, 7:113-117.

Genoways, H. 1973. Systematics and evolutionary relationships of spiny pocket mice, genus Liomys. Special Publication Museum Texas Tech University, 5:1-368.
Gillespie, T.W. 1994. A biogeographical and cultural ecological assessment of nature reserves on the island of Ometepe, Nicaragua. Tesis de Doctorado, California State University, Chico.

Gillespie, T. y B. Prigge. 1997. Flora and vegetation of a primary succesional community along an altitudinal gradient in Nicaragua. Brenesia, 47-48:73-82.

Haberland, W. 1992. The Culture History of Ometepe Island: Preliminary Sketch (Survey and Excavations, 1962-1963). Pp. 63-117, en: The Archaeology of Pacific Nicaragua. (Lange, F.W., ed.) Albuquerque: University of New Mexico Press.

Harvey, C.A., A. Medina, D. Sánchez, S. Vílchez y B. Hernández. 2006. Patterns of animal diversity in different forms of tree cover in agricultural landscapes. Ecologica Applications, 16:1986-1999.

Healy, P. 1980. Arqueología de la Región de Rivas, Nicaragua. Waterloo, Ontario: Wilfred Laurier University Press.

Horne, G.S. 1994. A mid-Cretaceous ornithopod from central Honduras. Journal of Vertebrate Paleontology, 14:147-150.

Houwald, G. 1975. Científicos y viajeros alemanes en Nicaragua. Pp. 1-9,en: Los alemanes en Nicaragua. Colección cultural Banco de América, Serie histórica $\mathrm{N}^{\circ} 2$. Editorial San José, Managua Nicaragua.

INETER. 1994. Diagnóstico. Estudio de Ordenamiento Territorial. Isla de Ometepe, Managua. Documento técnico.

IUCN. 2019. IUCN Red List of Threatened Species [Internet]. Versión 2011.1. Disponible 2019. <http:// www.iucnredlist.org/>. [Consultado el 10 de marzo de 2019].

Jones, J.K., Jr., y M.D. Engstrom. 1986. Synopsis of the Rice Rats (Genus Oryzomys) of Nicaragua. Occassional Paper Museum Texas Tech University, 103:1-23.

Jones, J.K. Jr., y C.J. Phillips. 1969. Zoological explorations in Nicaragua, Central America. Museum of Natural History, University of Kansas, 12-17. 
Jones, J.K. Jr., J.D. Smith y R. Turner. 1971. Noteworthy records of bats from Nicaragua. Occassional Papers Museum Natural History, University of Kansas, 2:1-35.

Jones J.K. Jr., y T. Yates. 1983. Review of the white-footed mice, genus Peromyscus, of Nicaragua. Occasional Papers the Museum Texas Tech University, 1-15.

Kirby, M. y B. MacFadden. 2005. Was southern Central America an archipelago or a peninsula in the middle Miocene? A test using land-mammal body size. Paleogeography, Paleoclimate and Paleoecology, 228:193-202.

La Gaceta. 2013. Ley No. 833. Ley que declara y define los límites de la Reserva de Biosfera de la Isla de Ometepe. La Gaceta-Diario Oficial 45, del 19 de febrero de 2013.

Levy, P. 1873. Notas geográficas y económicas sobre la República de Nicaragua. Paris, Librería española de E.D. Schmitz.

Loiselle, B.A., y J.G. Blake. 1991. Temporal variation in birds and fruits along an elevational gradient in Costa Rica. Ecology, 72:180-193.

López, M., S. Mandujano y G. Yánes. 2007. Evaluación poblacional del venado cola blanca en un bosque de la Mixteca poblana. Acta Zoológica Mexicana, 23:1-16.

Lothrop, S. 1998. Las culturas indígenas prehispanas de Nicaragua y Costa Rica. Pp.16-19, en: Culturas Indígenas de Nicaragua. (Arellano J. et al., eds.) Tomo I. Managua: Hispamer.

Lucas, S.G. 2014. Vertebrate paleontology in Central America: 30 years of progress. Revista Geologica América Central, número especial, 2014: 139-155.

MacArthur, R.H. y E.O. Wilson. 1967. The Theory of Island Biogeography. Princeton, NJ: Princeton University Press.

MARENA. 2016. Actualización del Sistema de Veda 2016-2017. Ministerio del Ambiente y los Recursos Naturales. La Gaceta diario oficial, resolución $\mathrm{N}^{\circ}$ 07.01.2016.
McCann, C., K. Williams-Guillén, F. Koontz, A. Roque y J.C. Martinez-Sánchez. 2003. Shade coffee plantations as wildlife refuge for mantled howler monkey (Alouatta palliata) in Nicaragua. Pp. 321341, en: Primates in fragments: ecology and conservation (Marsh, L., ed.). Kluver Academic Publishers.

McPherson, A. 1985. A biogeographical analysis of factors influencing the distribution of Costa Rica rodents. Brenesia, 23:97-273.

Medellín, R., M. Equihua y M. Amin. 2000. Bat diversity and abundance as indicator of disturbance in Neotropical rainforest. Conservation Biology, $14: 1666-1675$.

Medina, A. 2010. Mamíferos de la Isla de Ometepe, Rivas Nicaragua. Flora y Fauna Internacional $(F F I)$. Documento técnico insumo para la propuesta de Reserva de Biosfera de la Isla de Ometepe.

Medina-Fitoria, A. 2014. Murciélagos de Nicaragua, guía de campo. $1^{a}$ ed. PCMN/MARENA. Editora Dirección de Biodiversidad; Managua, Nicaragua.

Medina-Fitoria A. y O. Saldaña. 2012. Lista Patrón de los Mamíferos de Nicaragua. $1^{a}$ ed. Managua, FUNDAR N 599 M491.

Medina, A., C. Harvey, D. Sánchez, S. Vílchez y B. Hernándes. 2007. Bat diversity and movement in a Neotropical agricultural landscape. Biotropica, 39:120-128.

Medina-Fitoria, A., O. Saldaña, Y. Aguirre, W. Silva, F. Díaz, S. Hernández, C. Jordan, C. Cappello, M. Salazar, M. Chávez, J.G. Martínez y A. Gutiérrez. 2017. Libro rojo de los mamíferos de Nicaragua. Revista Nicaragüense de Biodiversidad, 30:1-85.

Medina-Fitoria, A., J. Martínez-Fonseca, A. Gutiérrez, E. van den Berghe, O. Jarquín, Y. Aguirre, M. Salazar, S. Robleto, N. Toval, M. Tórrez y F. Díaz. 2018. Las ardillas de Nicaragua (Rodentia, Sciuridae). Revista Mexicana de Mastozoología (nueva época), 8:48-80.

Morales, S., D. Osorno, W. Arendt y S. Hernández. 2007. Bird Checklist Ometepe Island Nicaragua. 1a ed., Managua. N 598.29 B618. 
Newmark, W. 1995. Insularization of Tanzanian Parks and the Local Extinction of large Mammals. Conservation Biology, 10:1549-1556.

Pelegrin, J.S., S. Gamboa, I. Menéndez y M. Hernández-Fernández. 2018. El gran intercambio biótico Americano: una revisión paleoambiental de evidencias aportadas por mamíferos y aves neotropicales. Ecosistemas, 27:5-17.

Rabinowitz, A. y B. Nottingham. 1986. Ecology and behaviour of the jaguar (Panthers onca) in Belize, Central America. Journal of Zoology, 210:149-159.

Redford, K. y J. Robinson. 1991. Park size and the conservation of forest mammals in Latin America. Pp. 227-234, en: Latin American mammalogy: history, biodiversity and conservation (Mares, M. y D.J. Schmidly, eds.) Norman: University of Oklahoma Press.

Rodríguez, K. 2009. Densidad poblacional del venado cola blanca (Odocoileus virginianus) en la Reserva Natural Volcán Maderas, Isla de Ometepe, Nicaragua. Tesis de Maestría. Universidad Nacional Costa Rica. Sistema de Estudios de Posgrado. Programa Regional Manejo de Vida Silvestre.

Serra-Vázquez, L. 2015. El Desarrollo histórico de la isla de Ometepe. 1a edición, Managua uca Publicaciones.

Squier, E. 1989. Nicaragua, sus gentes y sus paisajes. Trad. L. Cuadra, Managua Editorial Nueva Nicaragua.

Sunyer, J., S. Lotzkat, A. Hertz, D. Wake, B. Alemán, S. Robleto y G. Köhler. 2008. Two new species of salamanders (genus Bolitoglossa) from southern Nicaragua (Amphibia, Caudata, Pletodontidae. Senckenbergiana biologica, 88:319-328.

Vammen, K., P. Tercero, J. Montenegro y S. Guillén. 2006 Evaluación del Proceso de Eutroficación del Lago Cocibolca, Nicaragua y sus causas. Pp. 35-58, en: Eutrofización en Sudamérica: Causas, Consecuencias y Tecnologías para Manejo y Control. (José Galizia, ed.) Tundisi, Instituto Internacional de Ecologia de Sao Carlos.

Van Valen, L. 1973. Pattern and the balance of nature. Evolution Theory, 1:31-49.
Vílchez, S. 2005. Mamíferos del Volcán Madera. Plan de Manejo de la Reserva Volcán Maderas. Amigos de la Tierra-Fundación entre Volcanes. Informe técnico.

Weyl, R. 1980. Geology of Central America, translated from German. Gebrüder Borntraeger, Berlin y Stuttgart, Germany.

Williams-Guillén, K., C. McCann, J.C. Martínez-Sánchez y F. Koontz. 2006. Resource availability and habitat use by mantled howling monkeys in a Nicaragua coffee plantation. Animal Conservation, 9:331-338.

Wilson, D. y D. Reeder. 2005. Mammal species of the world. A Taxonomic and Geographic Reference (3rd ed.). Baltimore: John Hopkins University Press.

Winkler, L. 1999. Monitoring health, genetic diversity, movement, and fission-fusion patterns in a New World monkey (Alouatta palliata). Pp. 79-84, en: Investigation of animal movement: workshop proceedings (Huettmann, F. y J. Bowman, eds.) Sir James Dunn Wildlife Research Centre, University of New Brunswick, Fredericton.

Woodburne, M. 2010. The Great American Biotic Interchange: dispersals, tectonics, climate, sea level and holding pens. Mammalian Evolution, 17:245-264.

Woodman, N. 1998. Listado de mamíferos registrados durante mayo y junio de 1998 en San Ramón, Isla de Ometepe. Departament of Biological of Biological Sciences, Pennsylvania USA.: http:// vmaderas.tripod.com/inventarios/inventarios.html

Woodman, N. 2002. A New southern distributional limit for the Central American Rodent, Peromyscus stirtoni. Caribbean Journal of Science, 38:281-284.

Yates, T., H. Genoways y J. Jones Jr. 1979. Rabbits (Genus Sylvilagus) of Nicaragua. Mammalia, 43:113-124. 